\title{
Inbetweenness: Transcultural Thinking in my Compositional Practice
}

\author{
Lee Chie Tsang Isaiah \\ Borneo Heritage Research Unit, \\ Faculty of Humanities, Arts and Heritage, \\ Universiti Malaysia Sabah \\ e-mail: chie-tsang@ums.edu.my
}

Published online: 20 December 2018

Cite this article (APA): Lee, C.T.I (2018). Inbetweenness: Transcultural thinking in my compositional practice. Malaysian Journal of Music, 7, 134-158.

\begin{abstract}
This article explores the notion of 'in-betweenness' through transcultural thinking in my compositional practice. My thinking has been inspired by Tim Ingold's philosophical idea of 'wayfaring' as a way to navigate processes by which insights emerge from collaborative investigations. 'Interbreathment' is one of the earlier projects focusing on music and dance collaborations. Associated with a gong installation, this particular project explored a hybrid form of notation between musical and choreographical elements engaging with Chinese, as well as Malaysian indigenous cultural references (Kadazandusun) in which I sought a creative threshold for opening up new cultural dialogues to deepen my experience and understanding of the notions of entanglement and of how highly diverse elements can be unified through collaboration in my compositional work.
\end{abstract}

Keywords: collaboration, 'in-betweenness', transcultural practice, transmission,
transformation

\section{Introduction}

There is a difference between 'between' and 'in-between' ... Where between is liminal, in-between is arterial; where between is intermediate, in-between is midstream (Ingold, 2015, p. 147).

During the period of my $\mathrm{PhD}$ studies (2013-2018), I attempted to find creative perspectives intensely connected to experiences emerging from my cultural background. I am a fourth-generation member of the Chinese diaspora within a multicultural country, Malaysia, where a focus on differences between races, cultures, and religions strongly informs social and political relations. Within the 
context of a fairly young developing country that integrates a rich cultural diversity, the subject matter of making intercultural art and questioning definitions of cultural identity has over the years occupied the Malaysian artists who especially engage their creativity within the contemporary art world. One of the significant artistic movements happening in Malaysia is that local scholars, artists, musicians and composers have sought out a 'common language' and cultural identity across the country with which they can associate their work within the communal society, and thereby claim to be local artists. This social phenomenon is referred to Syed Ahmad Jamal, a senior Malaysian modern painter, who depicts the processes around cultural identity formation amongst artists as follows:

Contemporary Malaysian art has made its mark as an expressive form of the living national culture. In the short span of 25 years since Merdeka ${ }^{1}$ Malaysian artists have responded to situations and events in the developing nation. Malaysian artists currently move in various directions of commitment - drawing material from myths and legends, probing into questions of identity, regional cultural heritage, personal cosmology, ambiguity of pictorial space, social-political issues, contextual situations with Islam as central to artistic involvement, extension of calligraphic gestures, physical properties of material, dichotomy of traditional and contemporary values, etc. (Jamal, 1982) [cited in Khairuddin, N.H., Yong, B., \& Sabapathy, T.K., 2012, p. 16.]

Syed Ahmad Jamal's comment shows the great diversity of cultural sources that artists look to where it can be extremely difficult to find commonalities due to the many levels of social, religious and regional differences. The ideal of finding an emergent unity between differences, however, also raises questions around sustaining and transmitting very specific cultural practices to support community cohesion within a sometimes fragment identity politics and this has also been very much part of my everyday experience as an artist in Malaysia. Different waves and groups of 'powers' including a Malay-Islamic narrative of Malaysian art, a Chinese narrative of Malaysian art and a 'muhibah' ${ }^{3}$ version have been implemented across the nation since then and dominated the cultural discourse in various ways. The phenomenon of changing values and perceptions around a cultural story is illustrated in an article, 'Love Me in My Batik', written by Yee I-Lan (2012). She talks about how times and processes changed the cultural meaning and the identity of batik through forceful political events and activities, exploring how batik cloth falls into the embrace of popular culture as well as the machinations of state propaganda, becoming a kind of 'political kitsch' or a 'skin' veiling the concept of national identity and eventually transforming into a medium of sources, subjects and motifs in relation to one or other race, tradition, culture, locality and faith.

This notion of what can be recognised as a national artistic identity has become even more complex, challenging and problematic due to the fact that identity itself is constantly shifting and transforming from 'identity' into 'identities' (and vice versa) over time and from one generation to another. Composers based in West Malaysia-including Chong Kee Yong, Yii Kah Hoe, Saidah Rastam, Abdul Razak Abdul Aziz Johan Othman, and Tazul Tajuddin, whose musical works are 
strongly associated with intercultural elements-have drawn on diverse multicultural worlds to access materials whereby they could establish their musical language and identity. Their work has been given prominence, in particular with the emergence of a contemporary musical scene in Malaysia that can be dated to the first Kuala Lumpur Contemporary Music Festival, in 2009 (KLCMF 2009). ${ }^{4}$ By contrast, in East Malaysia, where I grew up in $\mathrm{Sabah}^{5}$, musical activity has been more researchoriented along ethnomusicological lines that focus on subject areas such as ethnicity, documentation, the popular music scene, and music education. There is, however, surprisingly little work written about compositional creativity, movements and practices, and specifically how composers engaging in a contemporary musical scene in Malaysia might tackle, integrate and develop their work and how they respond to the challenging task of cultural integration alongside with their artistic thinking.

\section{Finding the 'In-Between'}

The seeds of the work undertaken in this $\mathrm{PhD}$ project can be found in my master's thesis 'Chinese calligraphic thinking in my compositional work' (Lee, 2012). Although this previous research into how one's cultural 'mother tongue' can affect and stimulate one's compositional thinking, my subsequent work has moved into a much more hybrid and in-between space. I strongly resonated with eminent anthropologist Tim Ingold's idea of 'correspondence' in relation to the words 'between' and 'in-between', which expanded my thinking about intercultural dialogue.

The 'between' can be regarded as a 'bridge', an intermediate space in which one is able to link, join and integrate elements when corresponding with two different aspects at the same time. The 'in-between' has no particular 'object' or point of location; it does not have a specific 'connector' to enable it to correspond from two sides. The 'in-between' is a back-and-forth-interactive-space, a movement passing, twisting, and interacting directly without any absolute point, where one undergoes the movement of a process in an interstitial state of ongoing activity. Another interpretation suggested by Homi Bhabha (1994) is that cultural hybridity is continually shaped through an emergence within a three-dimensional world, the 'becoming' of itself. To me, both Ingold and Bhabha point out a new way of conceiving cultural hybridity, away from an interchange between terms to an interstitial world of becoming.

\section{Previous Works}

The breakthrough moment for me in terms of this shift in thinking occurred with my first cross-disciplinary project, Tōng-通- (2012), a ten-minute work and project commissioned by and involving the Asian Contemporary Ensemble (ACE). The project involved artists from different areas of artistic expertise and cultural backgrounds: a contemporary dancer, Tang Sook Kuan; a storyteller, Rosemarie Somaiah; and a conductor, Wong Kah Chun. It explores the Mengahau ceremony, celebrated by the Lotud people in Sabah, Malaysia. The unstable nature of such a 
rich project made me acutely aware of the impacts and changes I was undergoing. I had previously tried to avoid any uncertainty, especially with my plan to complete the music beforehand. What I discovered in the process of collaboration was that the music presented on the stage was no longer the same as it was originally planned, but it was 'becoming other'.

The 'becoming' or 'crossing-over' through collaboration with the dancer, the storyteller, the musicians and the stage itself during each session of discussion seemed to be re-identifying themselves naturally, even though no further changes were made to the musical notation. To me, this transformative experience- a piece of music eventually becoming another kind of work-was powerfully authentic. This realisation strongly relates to how Ingold describes the intimate relationship between 'making' and 'growing': "Moments of making punctuate the process of growing" (Ingold, 2015, p. 120). What I understand from this is that creative work can be thought of as cultivated rather than made, or the practice of making is the process of being responsive to conditions, to stimuli and opportunities for interaction that evolve in a similar way to how organic things grow in nature. The contribution of the other artists, for example in Tong-通- (2012), was not identified with any one individual at the final stage but made a new whole. I saw how I could unlock this new side of creativity, through a practice underpinned by co-creative contact and interpenetration with other creative energies.

From the musical point of view, thinking about 'growing' as an embryonic process of development of one's musical creativity brings to mind Bryn Harrison's statement that silence is not something that exists between events but rather its existence is pregnant with anticipation (Glover \& Harrison, 2013, p. 44). What Harrison mentions here is his experience of the space of silence in listening to Beuger's Calme Étendue (Spinoza) (1997). The point that interests me is how Harrison perceived the silence through the process of listening as the other 'world', which is being fertilised, particularly through his use of the word 'pregnant'. Harrison goes on to describe this musical world as a new 'life' that has been evolved by a continual progression through musical activity, which seems to me to be strongly related to the temporal idea of how an organic space is anticipated and reestablished. This abstract notion of 'reciprocal-association', or, so to speak, 'making-in-growing' and 'growing-in-making' has led me to investigate how a new musical identity can be created through collaboration, and this idea of parallel 'growing through living' processes provided me with another artistic perspective to think about cross-cultural and collaborative processes.

Drawing again on Ingold's work, specifically his lecture 'To learn is to improvise a movement along a way of life' (2010), I find highly appealing the idea that 'knowledge' is not received and cannot be transferred directly through any prespecified means from any traditional, theoretical, or systematic framework. Rather, creative knowledge is 'made' as a result of a continual movement of activities through which one is physically engaged and through putting oneself into the world of learning through practice. Ingold also argues that the essence of self-knowledge and one's creativity are actually not rendered directly either from the object or the person but through a process of 'growing' within. This notion of knowing, being 
involved and observing through learning, responding to and reflecting upon the world will then signify a direction, a path for someone from one stage to another, from one moment in time to another, until they reach the end of their 'finished' work. It is a journey of discovery through knowing the world or perhaps, as Ingold says, a 'guided rediscovery' in his lecture 'To learn is to improvise a movement along a way of life' (XdoctorbutcherX, 2010). What so interests me about this 'wayfaring' idea, however, is the process of its 'be-coming', which I can relate to my own process of creative evolution in which a diverse range of experiences of artistic interchange fertilised and guided the directions and development of ideas in my musical work.

The aim of this project, Interbreathment, therefore, is not to look at interculturality in terms of surface features of a specific contemporary musical style. It is inappropriate for me, at least at this stage, to establish a new musical grammar, compositional system, or any 'oriental' aesthetic so to speak, due to the fact that Interbreathment is the first attempt to know how I actually might operate in an intercultural world. Besides, I am also aware that this is not a means of corroboration of my compositions as musicological theory or framework. Therefore, the following project of this particular project will not apply and discuss directly any specific musicological framework but will rather focus more on the development of each work itself, bringing together discussion of compositional questions and methods, and thoughts from a range of philosophical areas. In terms of the methodology, I have applied Ingold's idea of 'wayfaring' to my own compositional process as a seemingly meandering journey through multiple cultural references that is about enrichment at every step rather than a focus on pre-determined goals.

\section{Learning Skills For Intercultural Exchange: Interbreathment}

[M] uch if not all of what we are accustomed to call cultural variation in fact consists of variations of 'skills'. By skills I do not mean techniques of the body, but the capabilities of action and perception of the whole organic being (indissolubly mind and body) situated in a richly structured environment. (Ingold, 2000, p. 5)

Tim Ingold's comment above suggests that it is the quality of perception and interaction of knowing and learning that enables one to relate to a practice of cultural exchange. He contends that distinctive cultural knowledge consists of different types of 'skill'. This is not a matter of learning a physical technique from others b,ut of building up a new form of 'skill' involving other modes of perception and different priorities. In other words, if one wants to have cultural exchange with others, one has to establish a new way of understanding by knowing the holistic relationship rather simply duplicating a physical technique. That is, to learn a new skill requires the ability to assimilate the other's cultural embodiment. This is a vital process to gaining awareness of a different cultural sensibility and knowledge. Although Ingold provides an anthropological view of technique in his writing, e.g.: The Perception of the Environment (Ingold, 2000), he does not, however, provide very specific examples about the process and the practice of how a new skill is actually embedded and made operational. This concern became my focus in a series 
of artistic collaborations.

\section{Background of Interbreathment}

In the summer of 2013, I invited the Malaysian dancer/choreographer, Tang Sook Kuan to collaborate with me on a project exploring these kinds of transformations through learning skills within cultural exchange. Interbreathment is an evening-long performance-installation piece exploring dialogues between music and dance. I wanted to increase my awareness of this highly complicated and challenging process of exploring how transcultural exchange and musical identity can actually be shaped and how choreographic ideas can be translated into musical ideas to create the form of a performance. In beginning my investigation, I take the word 'exchange' as something which can be understood as a process of alternation. In his article 'Identity and difference in a globalised world', Melucci (1997) said that 'Change is a goal that we find desirable and towards which our search for the new and different is directed'. In other words, change is an action of adjustment, blurring the identity of two sides in order to discover a new entity through which the adjustment contributed by both sides suggests and distributes an alternative result.

In my experience of collaboration, I have found it highly difficult to identify exactly what sort of exchange is taking place and what are the influences taken and distilled, especially when this process of transformation is saturated with dimensions of multi-cultural layers. As a young composer coming from a multi-racial nation, Malaysia, this idea of cultural entanglement is often held up as an ideal. Yet in practice, there are many areas of separation between cultures on the basis of ethnicity, religion and cultural traditions. The focus on interdisciplinary practice in my work, therefore, is a way of questioning and examining my assumptions about identity formation. This concept, through an ambiguous process of discovery that blurs something in order to unlock new layers of meaning, was central to my working process. I began my project by looking for analogues between my musical world and the physical world of dancers.

\section{The Collaboration Between Dancers and Musicians}

In his article, 'Choreographic objects', William Forsythe, the prominent American dancer and choreographer, says of choreography: "The word itself, like the process it describes, is elusive, agile and maddeningly unmanageable" (Forsythe, 2011, p. 90). Although the word itself, 'choreography', seemed problematic, complicated and challenging, I was fascinated by the organic process of the development and practice of its working, which Forsythe explained as follows: "choreography elicits action upon action: an environment of grammatical rule governed by exception, the contraction of absolute proof visibly in agreement with the demonstration of its own failure" (Forsythe, 2011, p. 90). I found a resonance with this element of uncertainty or rather dynamic fluidity, by which a dancer experiences, moves and choreographs his/her movement, and could connect it to the way I read a written Chinese character. That is, when Forsythe comments that "choreographic thinking being what it is, proves useful in mobilising language to dismantle the constraints of this 
degraded station by imagining other physical models of thought that circumvent this misconception" (Forsythe, 2011, p. 91), this, to me, is similar to the way in which the reading of Chinese calligraphy suggests other imaginative spaces.

In reading Chinese brush calligraphy, I find myself tracing the strokes with a kind of internal physical dance, mentally writing the strokes as I read. One can excavate the energy of these traces by experiencing the embodiment of the character through the process of writing in order to decode these 'imaginary routes' created by the strokes through reading. Ling Hwai-min, the artistic director of Cloud Gate Dance Theatre, explored this subject extensively in his Cursive Trilogy, a series of works based on Chinese calligraphy that combined the ancient practice of Chinese physical disciplines, including meditation, martial arts and Tai Chi Tao Yin, an ancient form of Chi Kung (Ya-Ping, 2009). To instil and penetrate these ideas and methods into one's physical body, Ling's strategy was to ask the dancer to imitate the trace of the marks in the calligraphic masterpieces by Wang Xizhi and others, as well as to study the Chinese calligraphy of Wei-chung Huang (Figure 1).

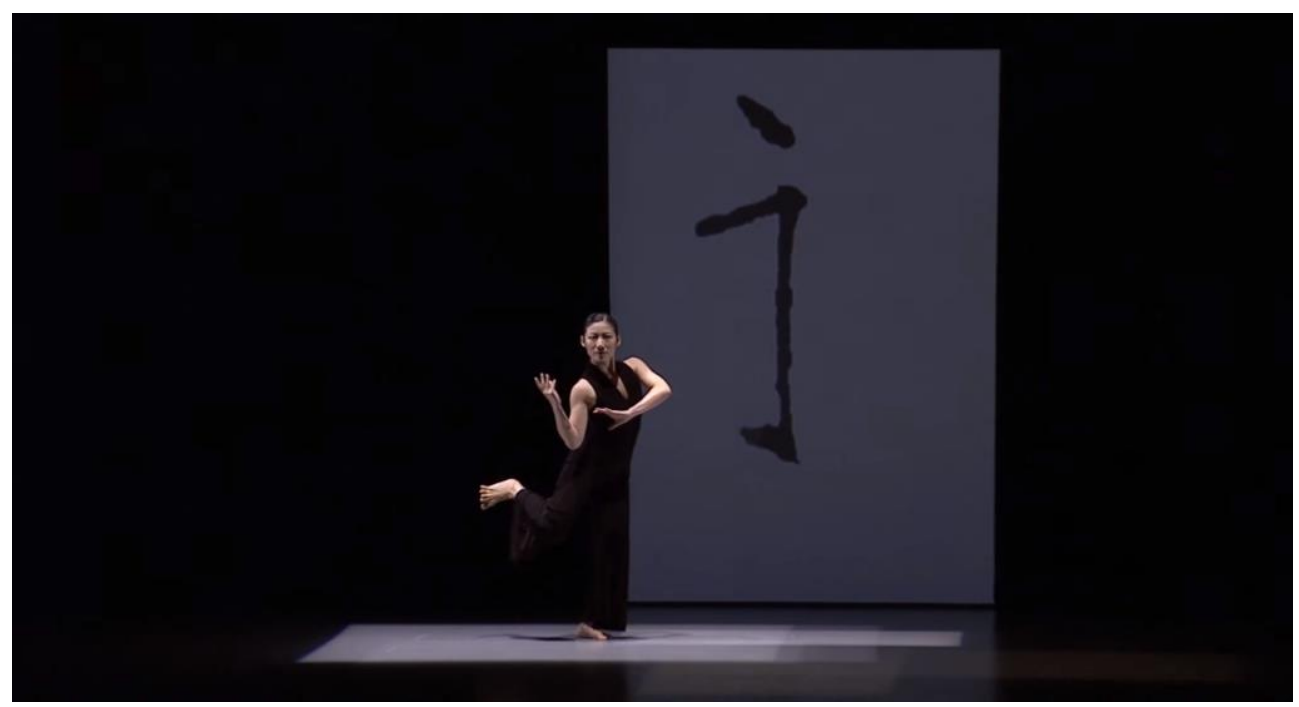

Figure 1. A scene taken from the first series of Cursive Trilogy, the cursive, one of a typified example demonstrating how the dancer uses her body as a metaphor to 'write' the Chinese character '永' ('eternity').

\section{Choreographical Notation}

The dancer adopts the style, shape, and dynamism of the calligraphy, copying the lines as if he or she was a student learning to write a piece of Chinese calligraphy and allowing the calligraphy to inform and articulate the choreographic grammar, including its rhythms, pulses and dynamics (Kin-Yan, 2010). In my own work, I began my first experiment by sorting out some of the musical as well as choreographical ideas and reformulating them into a kind of fragmented hybrid 
notation. My intention, however, is neither to create nor invent a new chorographical musical notation, but to use my musical experience and knowledge as a strategy for discovering the plausible potential relationship between language, sound, and movement in how choreographic ideas can be translated into musical ideas and vice versa. I wanted to find representations of visual and sounding elements as a creative way to open up, navigate, and unfold the collaborative dialogue in this project.

\section{(贡/貢)}

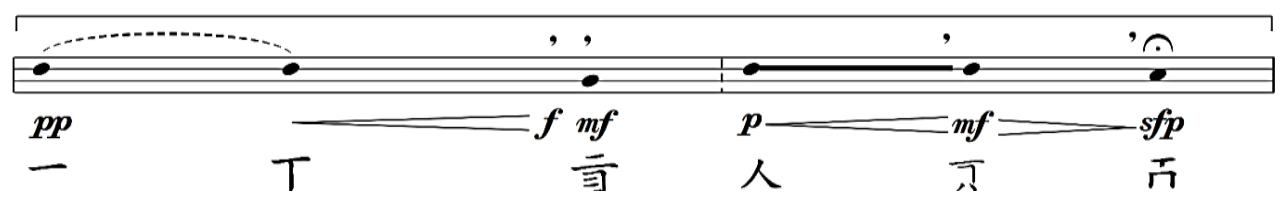

Figure 2. I took a Chinese poem titled '贡 (貢)。抗' written by Chong Kee Xin and fragmented its characters to create an invented choreographical notation (Figure 2) for Tang to read and work with.

$30^{\prime \prime}$

(哥)

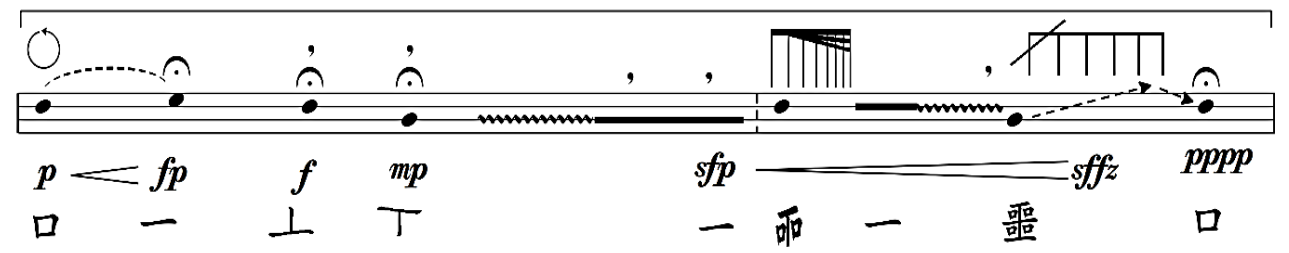

Figure 3. Alternatively, some of the characters might have only one writing form (Figure 3), represented as a single unit.

The Chinese characters played an important role in this score and are treated as the raw material for the notation. Each unit of the score is formed using two different writing forms: traditional and simplified forms of Chinese characters, shown within a bracket. Each of these characters has then been de-/reconstructed and subdivided later into different sizes and shapes, functioning as a musical pattern or phrase and serving as material for Tang to design her choreography.

The score, whose components look more or less like familiar Western musical notation, includes different ranges of dynamic marks together with a fourline musical staff. Each line indicates the approximate registers and positions (from low [on floor] to high [jumping]) that the body should execute, arrows to show changes in position, breathing indications, acceleration markings and fermatas, and these musical components were used by Tang as the basis for directing and creating her physical movements and gestures. These fragmented scores are the basis of the work's emergent structural form and meaning, which were then further reformulated, fragmented and re-joined, appearing later in different sizes to create 
new choreographic patterns, phrases and passages creating multiple relationships from a micro to macro level (Figure 4).
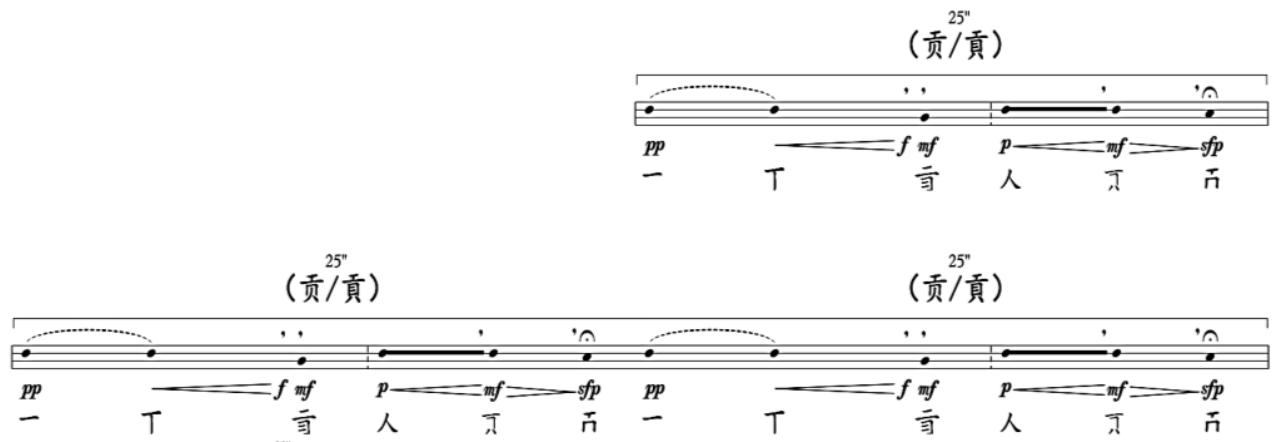

(垔)

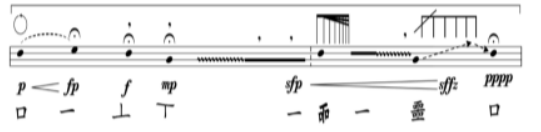

(垔)

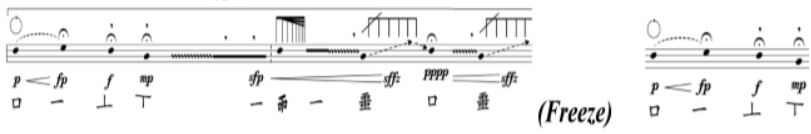

(阻)

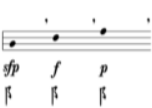

(Freeze)

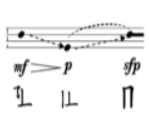

(Freeze)

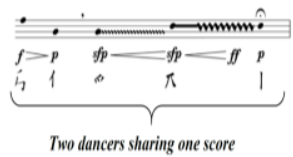

Figure 4. An extract of the score (reproduced version) illustrating the opening passage of the choreography starting from a solo dance followed by a duet form. Another example (reproduced version) showing how the fragmented notation is reshaped and extended to a larger scale.

The process of working with this hybrid notation allowed us to combine mixtures of physical and musical elements crossing simultaneously with Chinese linguistic and sounding elements held by the written characters themselves. The result was a highly complex sense of multiplicity. While reading and interpreting these characters, there were challenges to processing the information across the different meaning levels of the notation due to the hybrid notation and the material itself being highly spatial and inflected. For the choreographer, movements that have been constituted with several dimensional layers of parameters, including facial expression, body movement, dynamics, speed, gestural form and shape, cannot be fully captured and expressed on paper. Unlike a conventional Western music notation in which each note represents a single unit of sound, marks such as a note-head in this case encapsulate multiple layers of activities and impulses shared across three different logical models: language, sound and movement. Each of these, however, fuses together rather like a 'chord' or a 'cluster' rather than projecting as a 'single-tone' concept.

My intention was neither to create a style nor constrain movement but to 
create a situation for stimulating the movement of creative imagination through a process of 're-learning'. The structure as well as process of working with the notation was quite flexible due to the openness and ambiguity of the material itself. After a brief description through communication, there were no further explanations indicated in these initial fragmented-scores. Tang started her first experiment by reimagining and transforming her body and movement like a Chinese calligraphic brushstroke to 'read' and 'write' the score as a series of tracings. However, because the original meaning, context and logical structure of the Chinese character had been disrupted, the structure of these new forms of the characters gave rise to passages of activity whose interior 'pillars between the joins' seemed to offer new insights into the meaning of the poem. In other words, in order to access the information of these new Chinese characters, Tang and I had to learn seemingly familiar words in a new way.

Tang's approach was to reorganise my sketch fragments of a dance notation into her own version, which she wrote out on A3 size paper (Figure 5).

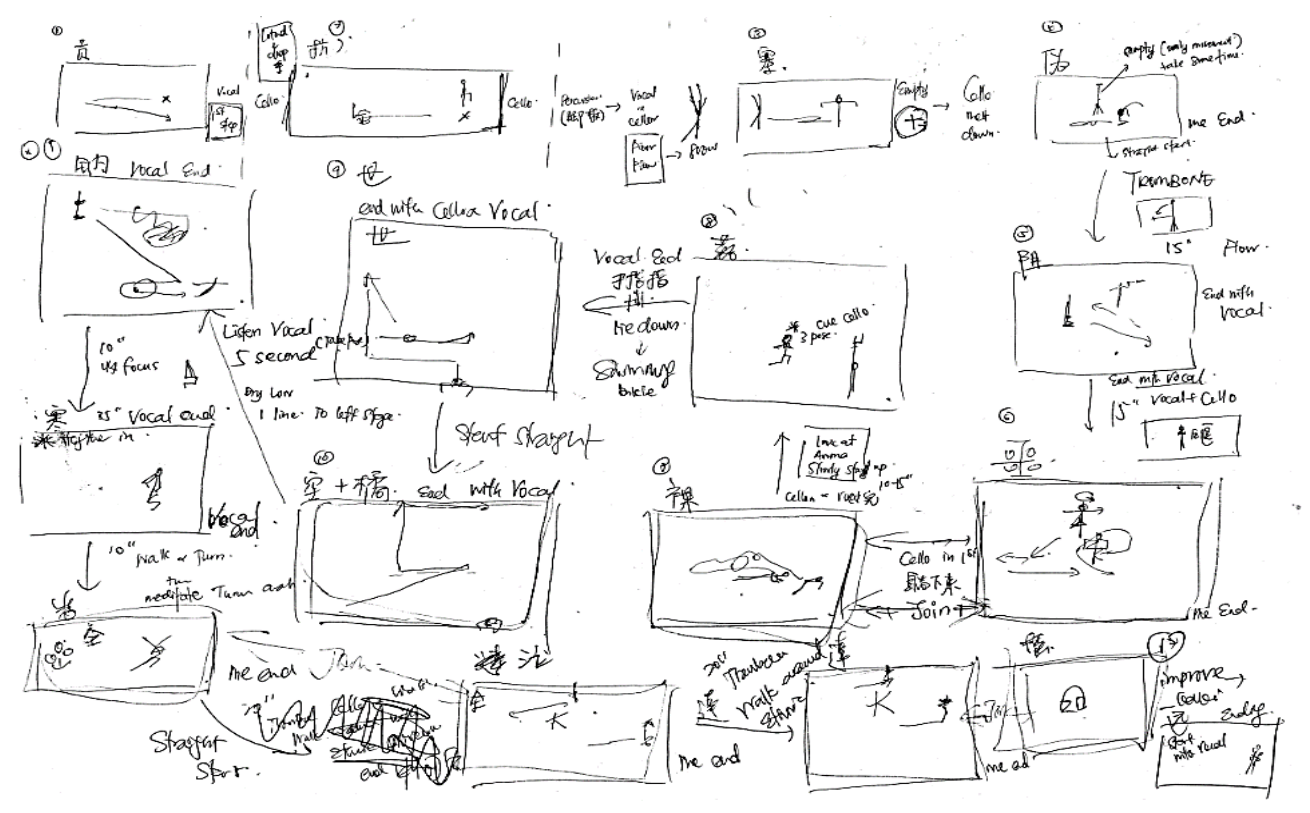

Figure 5. One of the early sketches illustrating how Tang translated and reformulated her chorographical ideas from the notation I created.

What I found particularly interesting about her sketch is the way in which she created an interlocked relationship amongst the characters by weaving together the units. She therefore expanded the complexity of the connections and the networking between the elements of the score fragments that I had provided. Her sketch, which then replaced my first notations as the reference score, became the central medium for communicating our developing ideas for navigating our later discussion and negotiation. This process of transformation through translation can 
be seen as an example echoing my earlier idea of wayfaring of how one's creativity can be (re-)emerged and (re-)established organically by others through working process(es) through which one's authenticity as well as their territory has been blurred and re-contextualised.

\section{Creating a Gong Installation}

At a centre of the work is a set of 52 Kadazandusun traditional gongs, new and old, of different sizes and with different tunings, which are suspended throughout the performance space (Figure 6).
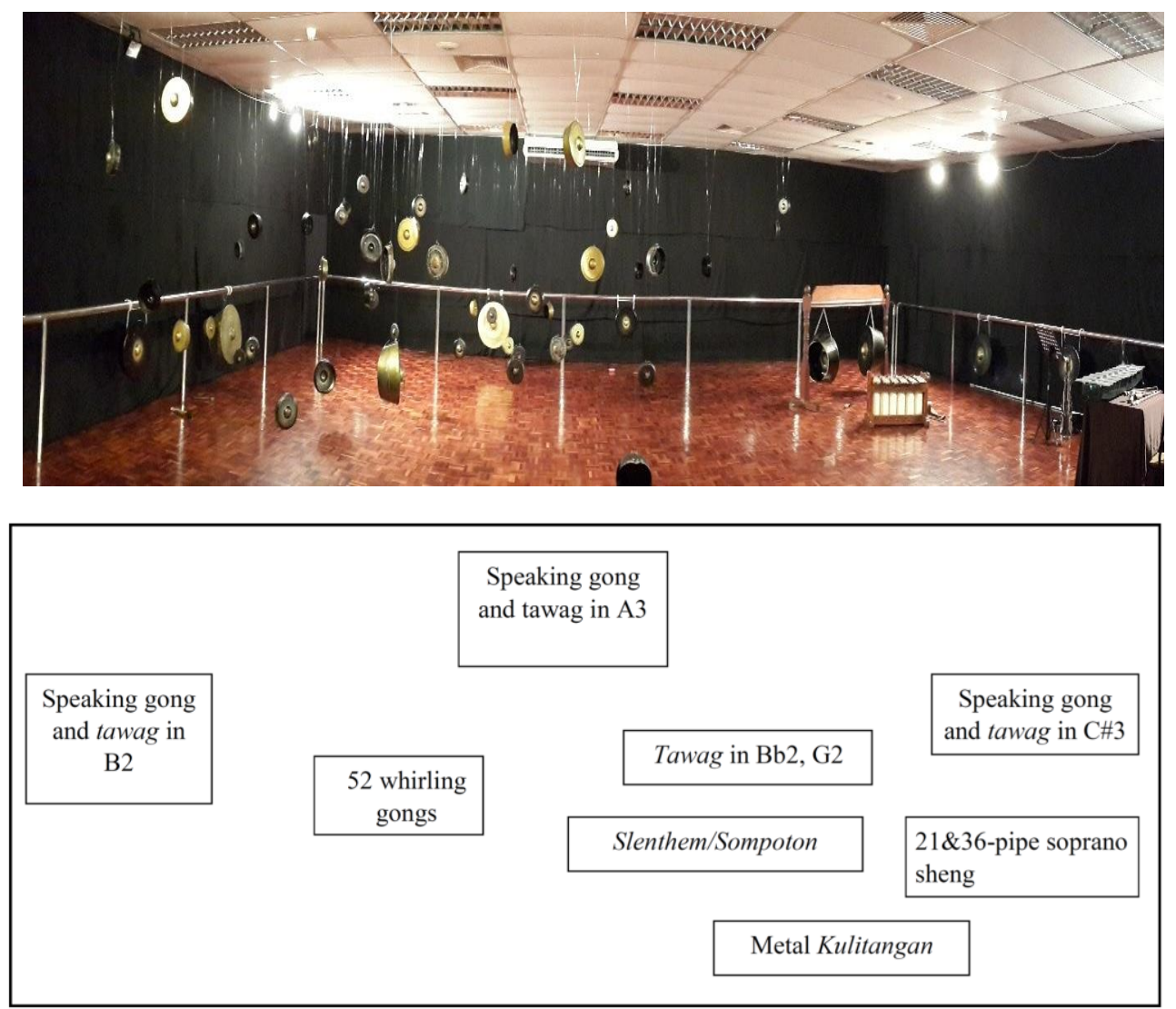

Figure 6. The final appearance setting of the gong installation, and the diagram of distribution.

Two dancers and three musicians move through this gong installation. Each musician are set at the right-hand side of the space, playing different instruments and also moves in the space performing with the dancers (Figure 7). 


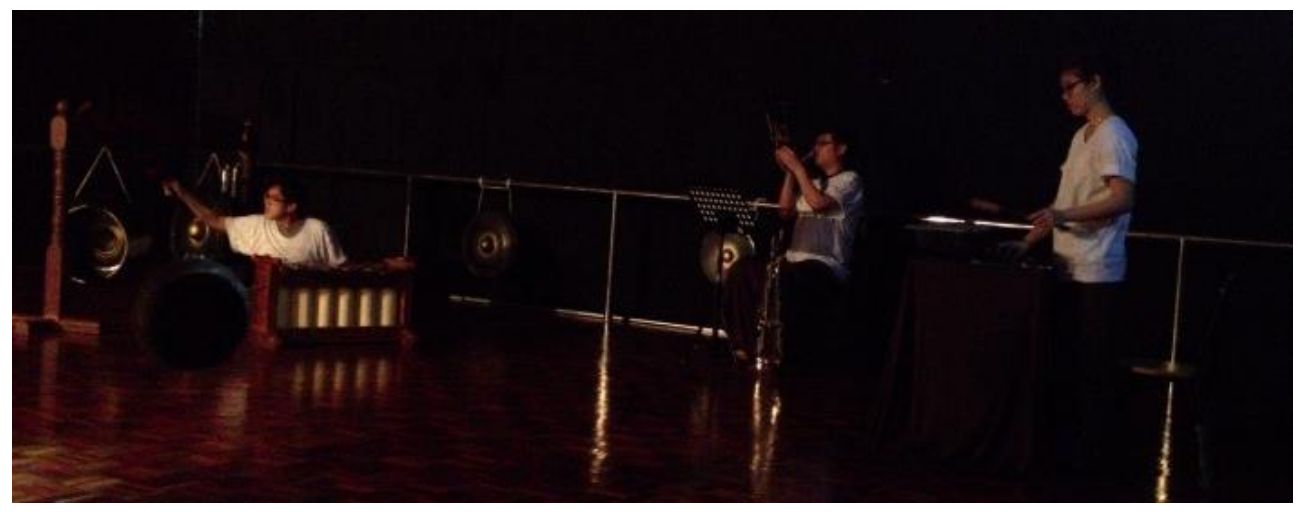

Figure 7. Performer 1: 2 gongs in $\mathrm{B}^{\mathrm{b}} 2$ and G2 (behind the slenthem), 2 gongs (speaking gong and normal tawag in $\mathrm{C}^{\sharp} 3$ ), slenthem pentatonic in $\mathrm{C} 2$, sompoton (traditional kadazandusun bamboo mouth organ). Performer 2: 21-pipe soprano sheng and 36-pipe soprano sheng. Performer 3: 1 gongs (speaking gong and normal tawag B2), metal kulintangan. One of the dancers also plays together with the musicians in the fifth section [the dance solo]: 2 gongs A3 (speaking gong and one normal tawag).

The gong can be considered the most important musical element symbolising the core of the musical culture among the Indigenous people of the Malaysian and Indonesian archipelago - what the German ethnomusicologist Abels calls 'The so-called gong-chime belt of Southeast Asia' (Abels, 2015, p. 33). ${ }^{6}$ My journey in forming this gong installation can be traced to the discovery of what I called the 'speaking gong', a very unique set of traditional Kadazandusun gongs with complex and mobile sounds found in a costume storeroom at the University of Malaysia, Sabah (Figure 8).

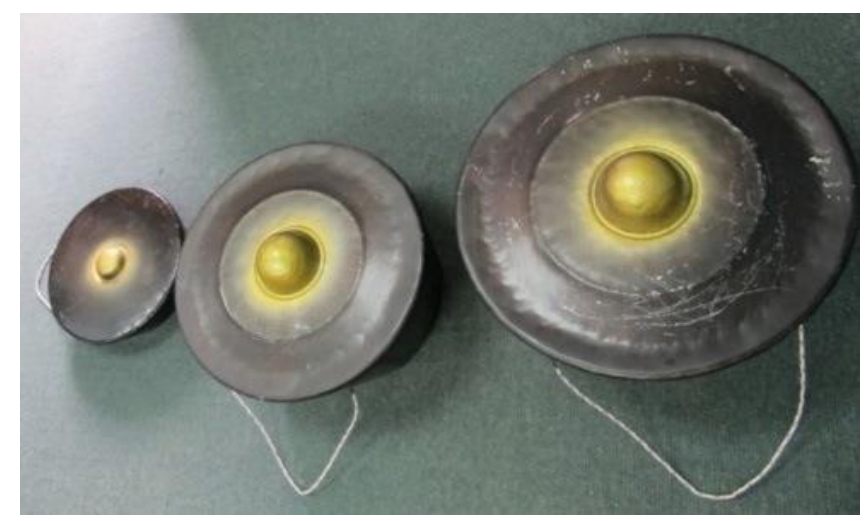

Figure 8 . The three speaking gongs.

There is nothing extraordinary about these gongs at first sight. The design of these instruments, in fact, is similar to other gongs except that these three are 
profoundly exceptional and unpredictable in their sound. It seems to me that these gongs had been stored because of their faulty distorted sound, but this was exactly what fascinated me as a composer to explore how to transform these 'failures'.

These three gongs produced a very interesting multiphonic texture projecting a two-dimensional musical layer simultaneously including a sustained tone and a glissando tone (from low to high). The glissandi of each gong, however, are quite flexible and adjustable in their interval within a range of approximately a minor third, determined by the dynamic level with which they are played. For example, the smallest of these three gongs (sanang) produces an approximate end pitch of $\mathrm{A} 3$ with a minor $3^{\text {rd }}$ glissando effect starting from $\mathrm{F}^{\sharp} 3$ (Figure 9).

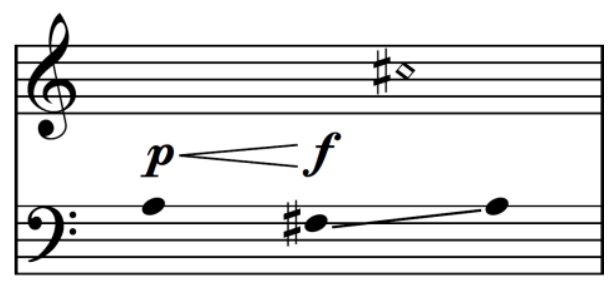

Figure 9. The musical texture created by the sanang.

The proximity of this interval, however, depends on the dynamic; the louder the gong is played, the wider the interval. When the gong is played even more loudly, it will produce a $\mathrm{C}^{\sharp} 5$ pitch, which sounds together with the changing tone.

In order to revitalise the faulty identity of these speaking gongs, I reviewed and formulated the traditional concepts of the gongs' identity and functions as follows. Firstly, the gong is an object to produce sound and used to provoke a sense of one's cultural identity, especially as a stimulus for tuning one's imagination in the live performance of ritual. Secondly, without further discussing the detail about the complexity of the gong's spectral structure, despite the exceptional cases of the three speaking gongs with their complex effects, each gong basically represents a single unit of sound which only forms part of a motive, or pattern when played in an ensemble. This principle is found in most of the Southeast Asia region, especially in gamelan music. In most of these traditional gong repertoires, highly complex musical textures are created by using interlocking techniques to create different patterns, textures, and layers as the foundation of the musical practice. Thirdly, the physical mobility of the gong is limited. Since the gong functions primarily as an accompanying musical instrument, basically, its location on the stage is fixed, and there is generally no physical movement with the instrument.

To break down the barriers, as I started to become more aware of the relationship and the impact of the entanglement between the instruments and the performers within a performance stage, I sought to remodel the image of these gongs by re-considering the meaning of their spatiality and identity, and by repositioning them. My first approach was to unlock the gongs from a traditionally static position by rethinking the gong as a living object instead of just an accompaniment to dance performance. This notion of thinking the gongs as part of 
the body of the stage instead of as instruments, moving from an 'ensemble' to a 'stage', eventually led me to the direction of creating a gong installation which then became an essential element of the articulation of the space through which the dialogue of the creativity of our collaboration unfolded.

The interior architectural concept of the gong installation was derived from the form of the Chinese traditional audience chamber (Figure 10), which was adopted to form the installation's outer structure by coupling each speaking gong with another tawag, hanging and placing them on the barre at different corners (on the left, middle and right side) of the stage (Figure 6).

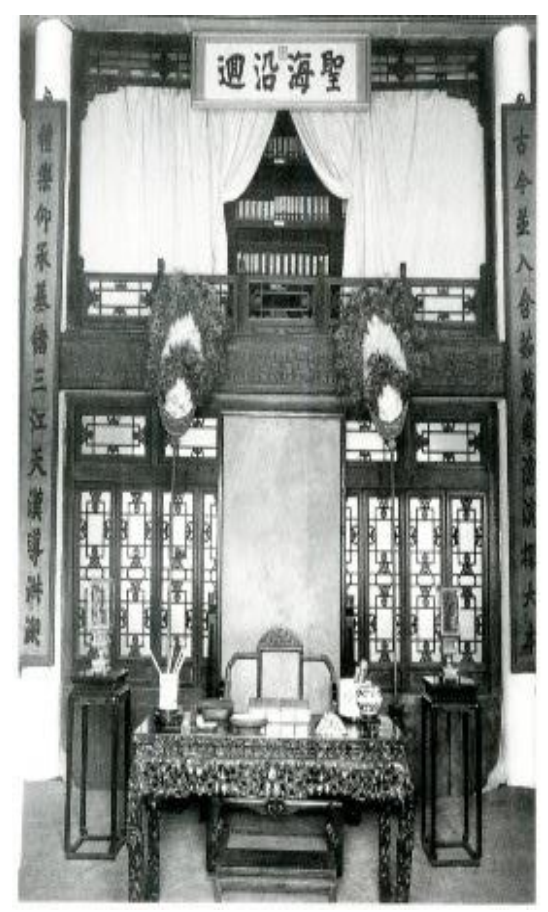

Figure 10. Wen-su-Ko library, Ch'ing dynasty, 1782, interior view of audience chamber, Shen-yang, Liaoning. From Chung-Kuo mei shu ch'üan-chi, chien-chu i-shu pien, vol. 1, Kung-tien chien-chu (Peking: Chung-Kuo chien-chu kung-yeh ch'u-she 1987), pl.153 (Carey, 1999).

The positioning of the musicians and the speaking gongs was inspired by the spatial arrangement of furniture, scrolls and Chinese calligraphic couplets in traditional Chinese interior design (Figure 11). 


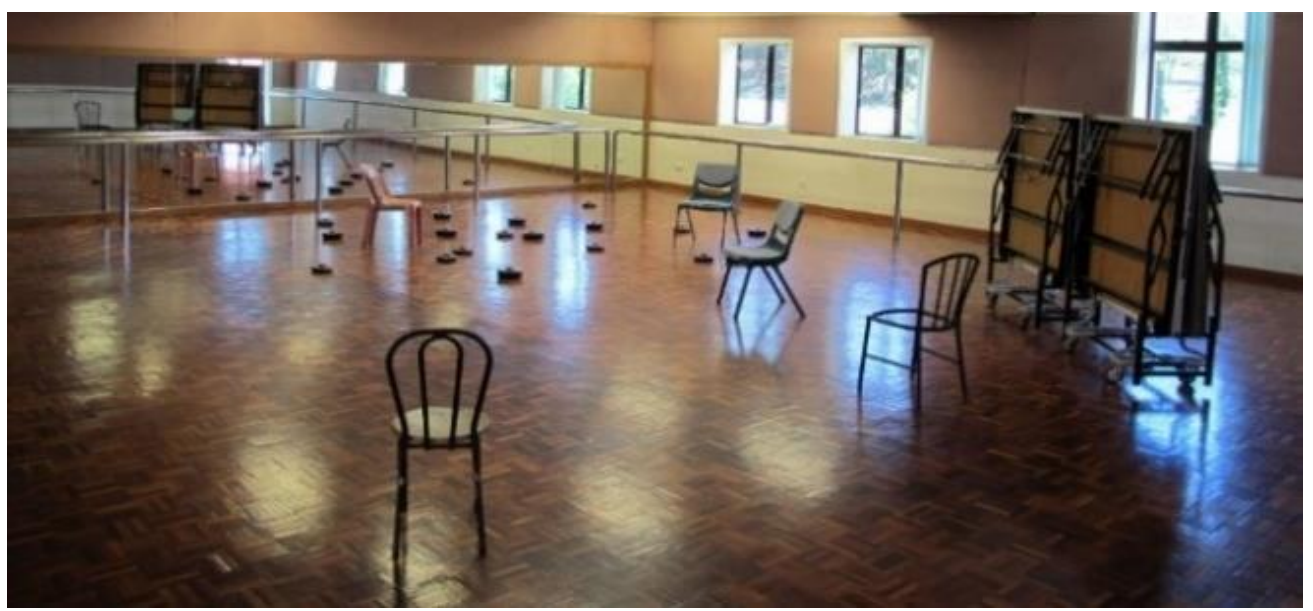

Figure 11. Sketching the gongs' positions on stage based on the arrangement of the Chinese audience chamber.

This arrangement was used to harmonise and incorporate the forces between the positive and the negative energies represented and generated by the musicians and the dancers within the stage. Aside from the three speaking gongs, we collected 52 different new and old kulitangan ${ }^{7}$. Each of these gongs was then distributed and hung in the room to articulate architectural space, forming a kind of 'body' with which the dancers and musicians could interact (Figure 12).

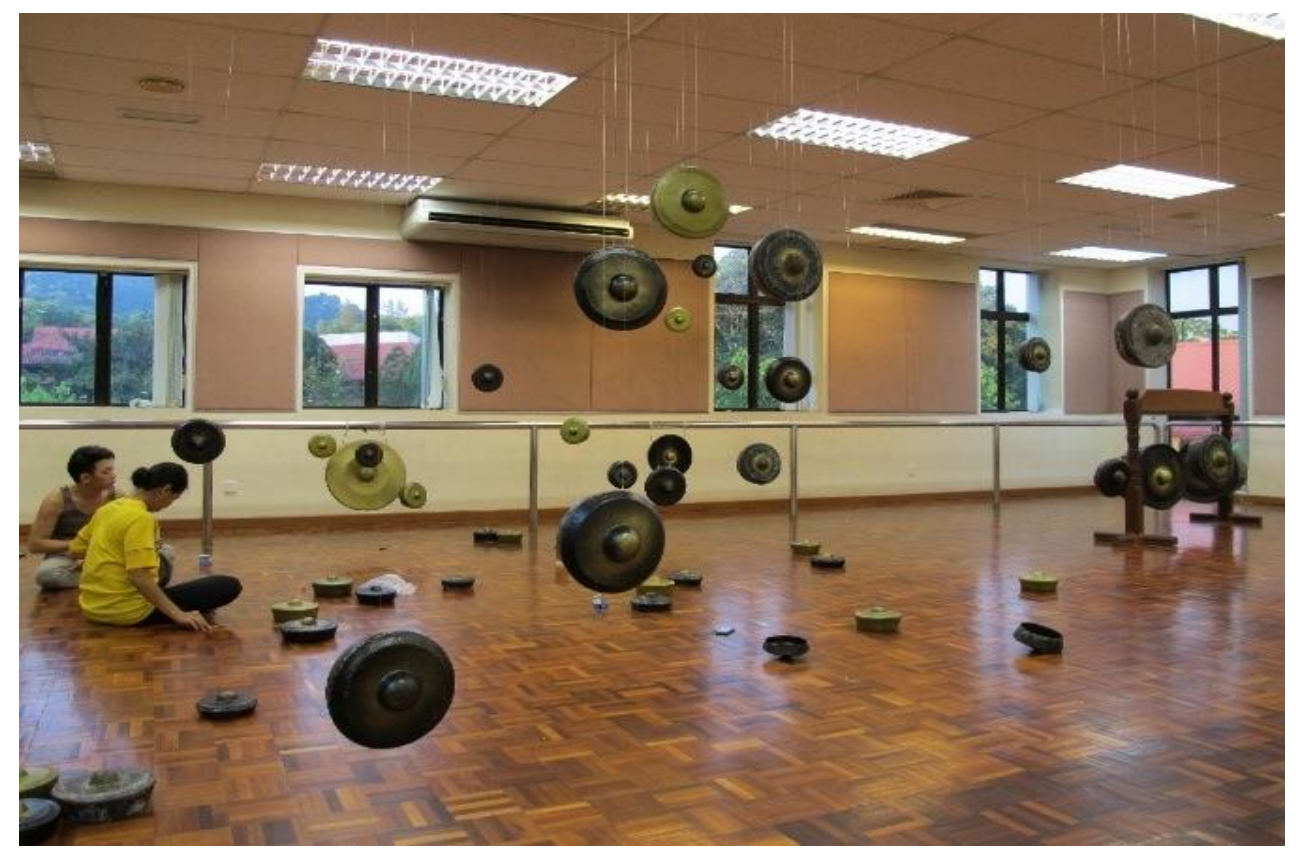

Figure 12. The whirling kulintangan. 
Suspended in the space, these whirling kulintangan take on a very expressive life and seem to 'speak' with many inflections of sound in the space, creating a visually spectacular mobile environment for the performers in which either side of the gong can be sounded and the sound dispersed by swinging and spinning the gongs.

In response to Ingold's discussion of how one's experiences, knowledge and creativity are accumulated and shaped organically by the changing context of the environment, and to deepen my transcultural understanding through exchange, I invited musicians to participate in the process of making music together with the dancers in a sequence of workshops.

Over time, this implementation gradually formed a reciprocal relationship, in which I strongly experienced a kind of alchemical exchange as dancers and musicians started experimenting by assimilating each other's performative embodiment. Through my observation, this choreographic activity then seemed to transfer into the musicians' bodies. For example, one of the musicians who played the metal kulintangan seemed to have applied this 'skill' in their musical performance practice. During the working process, she assimilated Tang's experimental behaviour and her choreography into her practice, using beaters to rub across the surface of the metal plates in a circular motion whilst moving and changing the positions of the metal kulintangan to create different forms of modes with which her musical material in the later live performance is associated. As the pitch order of the instrument was constantly re-organized throughout the performance, it created interesting musical patterns and textures, a ripple-like effect between pitches and noises just as Tang created noises as she adjusted the gongs on the floor.

From these collaborative workshops I created a constellation of musical events and decided to weave all the findings, experiences and knowledge I had discovered and learnt throughout the working process by staging a performance to broaden the surface between my artistic perception and physical experience. For the finished work, I staged the reciprocal relationship of elements to unfold the musical as well as choreographical activities of the previous workshop stages. This allows the performers to generate and operate the vocabularies between sound and the movement in a live situation, and so further unlock and open up the conversations between all these elements. I did this without assigning any written specification or using a musical score but through a process of exchange incorporating ideas from all participants using words, notes and sketched diagrams. This communication greatly enriched real-time performance reactions from the performers. 


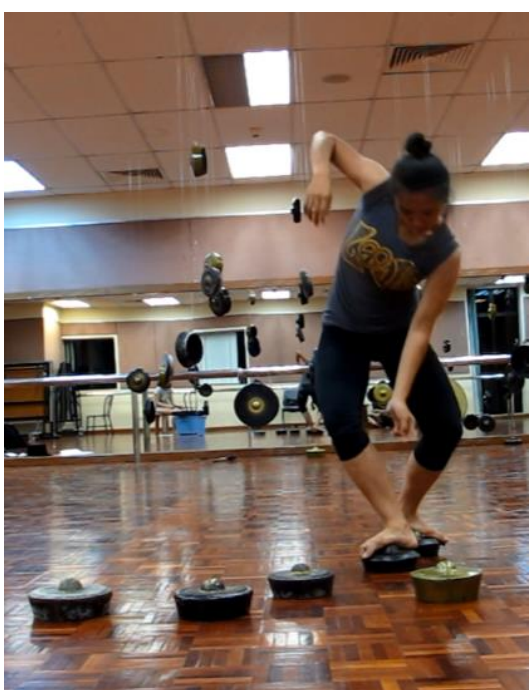

Figure 13. Tang selected five different kulintangan with different pitches, placed them on the floor, and experimented with her choreography by using the surface of the body of the kulintangan to create different platforms.

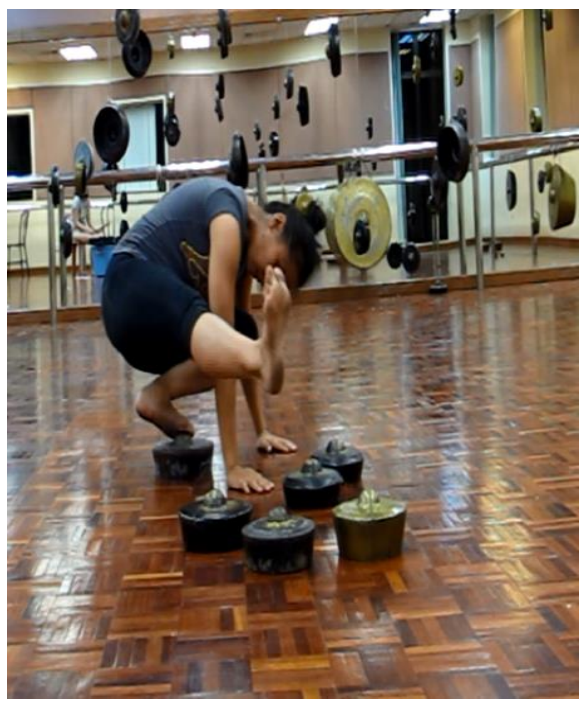

Figure 15. A scene showing how Tang explored other possibilities by moving away the instruments.

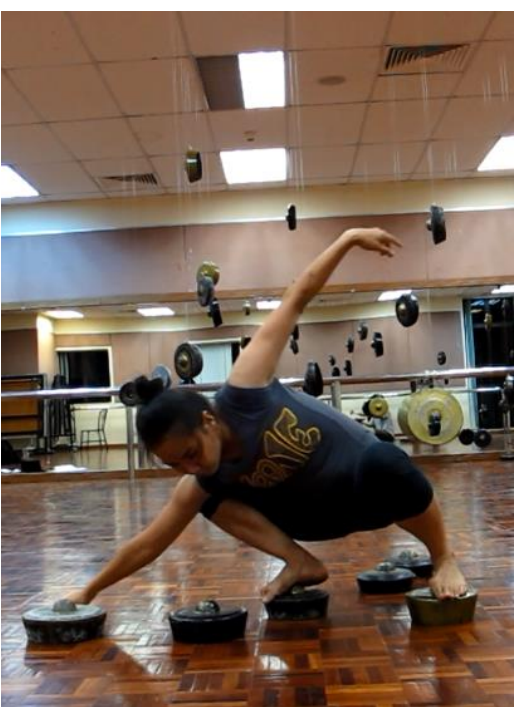

Figure 14. A scene showing how the instruments led Tang to experience different body movements and affected the way she choreographed her dance. This is especially when Tang moved and readjusted the spaces between each instrument.

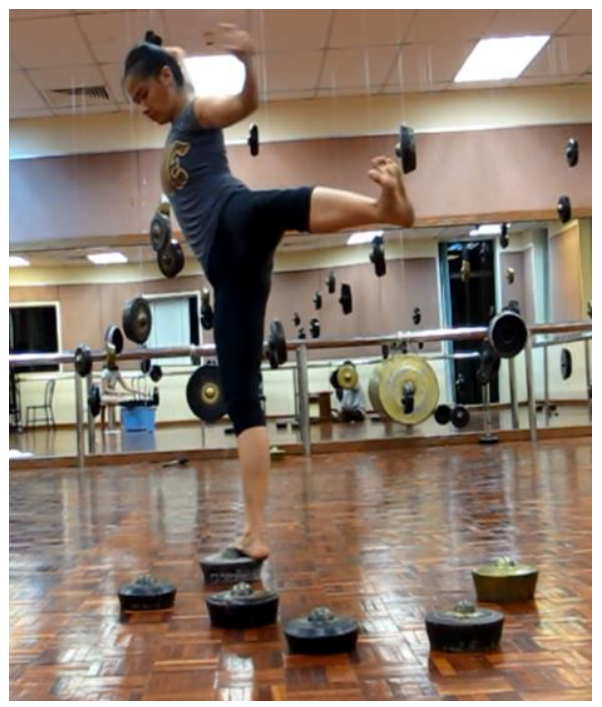

Figure 16. A moment showing how Tang experimented a rather challenging choreographical gesture. 
Table 1

The structural form of the 23-minute performance-installation piece can be divided into six sections indicated with different themes with an approximate timeline. (*) each event's total approximate duration (**) approx. starting time in the video

\begin{tabular}{|c|c|c|c|c|c|}
\hline $\begin{array}{c}\text { First event } \\
(* 4 \text { mins })\end{array}$ & $\begin{array}{c}\text { Second } \\
\text { event } \\
(* 1 \text { min })\end{array}$ & $\begin{array}{c}\text { Third event } \\
(* 4 \text { mins })\end{array}$ & $\begin{array}{c}\text { Fourth } \\
\text { event } \\
(* 4 \text { mins })\end{array}$ & $\begin{array}{c}\text { Fifth event } \\
(* 5 \text { mins })\end{array}$ & $\begin{array}{c}\text { Sixth event } \\
(* 6 \text { mins })\end{array}$ \\
\hline$(* * 00: 00)$ & $(* * 03: 30)$ & $(* * 04: 30)$ & $(* * 08: 40)$ & $(* * 12: 36)$ & $(* * 17: 10)$ \\
\hline The opening & $\begin{array}{c}\text { Tracing the } \\
\text { mark of the } \\
\text { space and the } \\
\text { spacing } \\
\text { within the } \\
\text { stage }\end{array}$ & $\begin{array}{l}\text { The whirling } \\
\text { kulintangan }\end{array}$ & $\begin{array}{c}\text { Choral } \\
\text { section }\end{array}$ & $\begin{array}{c}\text { The dialogue } \\
\text { between the } \\
\text { speaking } \\
\text { gongs, } \\
\text { dancer and } \\
\text { sheng }\end{array}$ & $\begin{array}{c}\text { The } \\
\text { conversation } \\
\text { between the } \\
\text { whirling } \\
\text { kulintangan }\end{array}$ \\
\hline
\end{tabular}

In terms of form, these events are not designed for rigidity or for restrictive purposes but were a means of creating a situation to navigate amongst multiple voices in this project where performers could express themselves and correspond with others within an open interactive space. While structuring these events, I also chose to unfold the dialogue between the dancers, the musicians and the gong installation in a more flexible way, allowing a certain freedom of choice for the performers to channel and strengthen their ideas and energy easily through these activities, although there are several fixed choreographic events between the sections. In a sense, the stage itself was treated as an opened-ended score: the movements, sounds and energies become part of the materials - components or parameters within the notation. In other words, the stage can be seen as a 'moving' score. Although each event in the diagram above appears to be a discrete structure with a strong narrative form, my idea is that these musical events are not meant to be separated but should be seen as comprising a whole within which the energies articulated and shared between the events are interconnected. During the performance, each performer has to observe and listen to how others contributes and elicits reactions. This idea was inspired by the first score I made for Tang in which I wanted to bring a notion of symbiosis to how elements and people relate underlying a mutual sense of understated, implied conversation.

The first event provokes a sense of 'in-betweenness', of crossing worlds between static and non-static states. A feeling of past, present and future co-existing through breathing, waiting, and moving can be considered the prelude in this performance (Figure 17). 


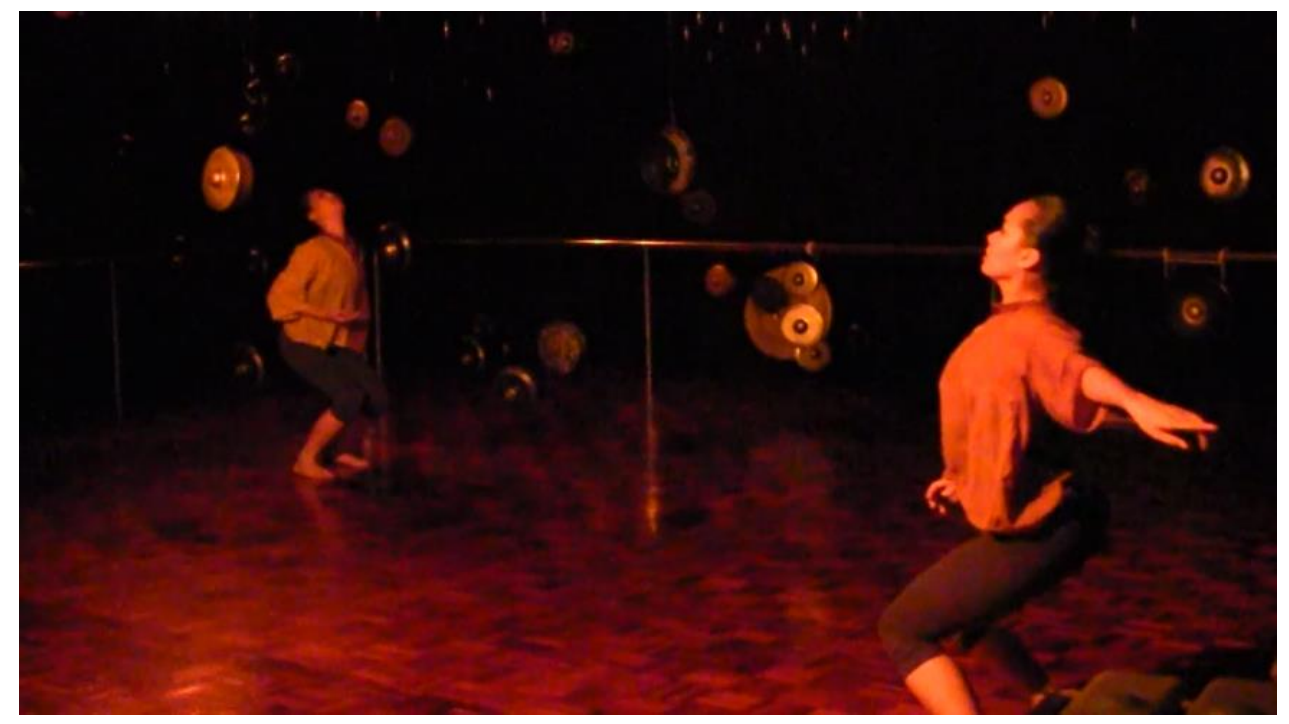

Figure 17. A scene taken from the beginning of the first event capturing the moment in which the dancers use their breathing as a signal for communication purposes during the performance.

The opening with the kulintangan and the slethem creates a long duet passage with bow whilst the dancers remain still. Following this is a long canon-like choreographic passage created by the dancers, projecting sometimes mirroring/symmetrical patterns as well as traditional Kadazandusun choreographic gestures combined with movements crafted from the earlier sections. This choreographic pattern, interpenetrated with a sometimes improvisational language, is articulated using breathing as the synchronizing factor. The performers adjust their body rhythm, energy and articulation during the performance. Through this, the dance creates signals for the musicians who respond with a rather slow, calm, meditative sort of musical situation and atmosphere.

Begun and led by the dancers, the second event is a short transition to the following section in which the dancers freely criss-crossed the stage without touching the instruments. The dancers proceeded by transforming their body movements, imitating the gestural movement of the twirling gong, using the spaces in-between the whirling gongs hung on the stage accompanied by an intermittent repetitive pattern of sounds created by the sheng (Figure 18). 


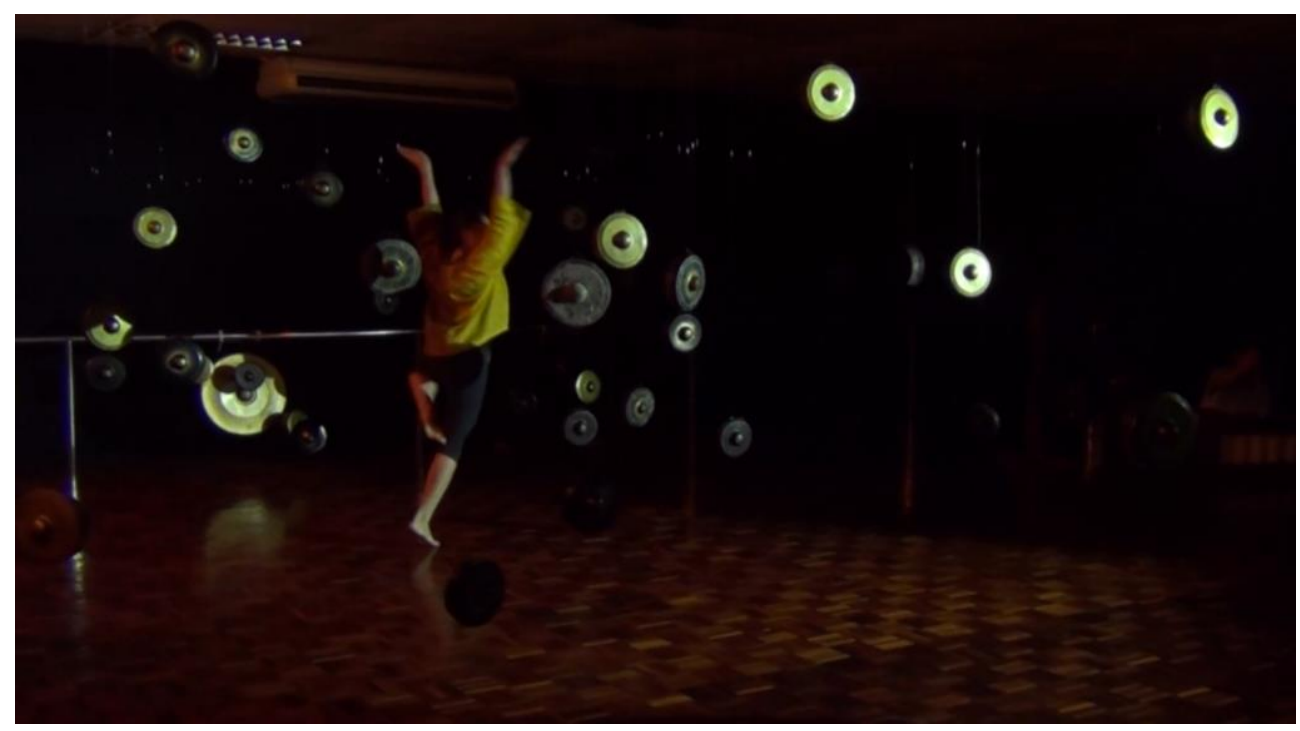

Figure 18. A scene from the second event portraying the moment how the dancer assimilated the movement of the whirling gongs into their physical body.

This activity has been terminated slowly in the later passage as the performers shift to the beginning of the third event, which begins with a storytelling-like situation in which the performers transform their bodies into gongs and start making contact with them by holding them and covering their face with them like a mask whilst reciting a short poem about the Kadazandusun creation story (Figure 19).

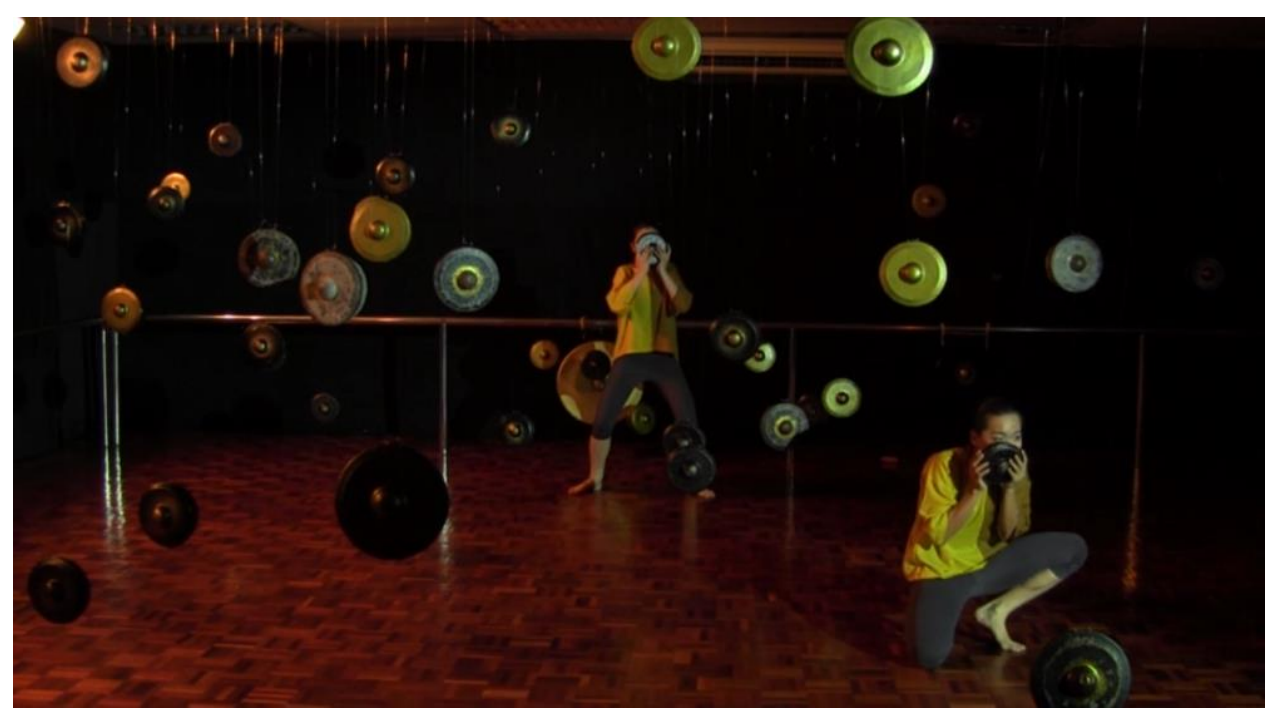

Figure 19. A scene showing the dancers reciting poems to the kulintangan about the kadazandusun creation story. 
Having been twisted in the air after the recitation, each spinning whirling gong here creates an interesting visual effect resonating to the live music created from the ensemble as if they were speaking, talking and interacting with others. This interactive activity creating a sense of confusion resulting in an interesting spatial effect with energies intertwined between the visual, sonic and kinetic elements throughout the process in which the intensity of the music from the ensemble as well as the dynamism of gongs on the stage are gradually raised to the extent where the dancers started speeding up their activity.

The fourth event extended the performers' voices, creating a ritualceremonial atmosphere, by bringing the musicians onto the stage with the dancers to perform, interact, explore and operate different sound worlds within the gong installation, enriching and bridging their performances by creating an imaginary 'choir' (Figure 20).

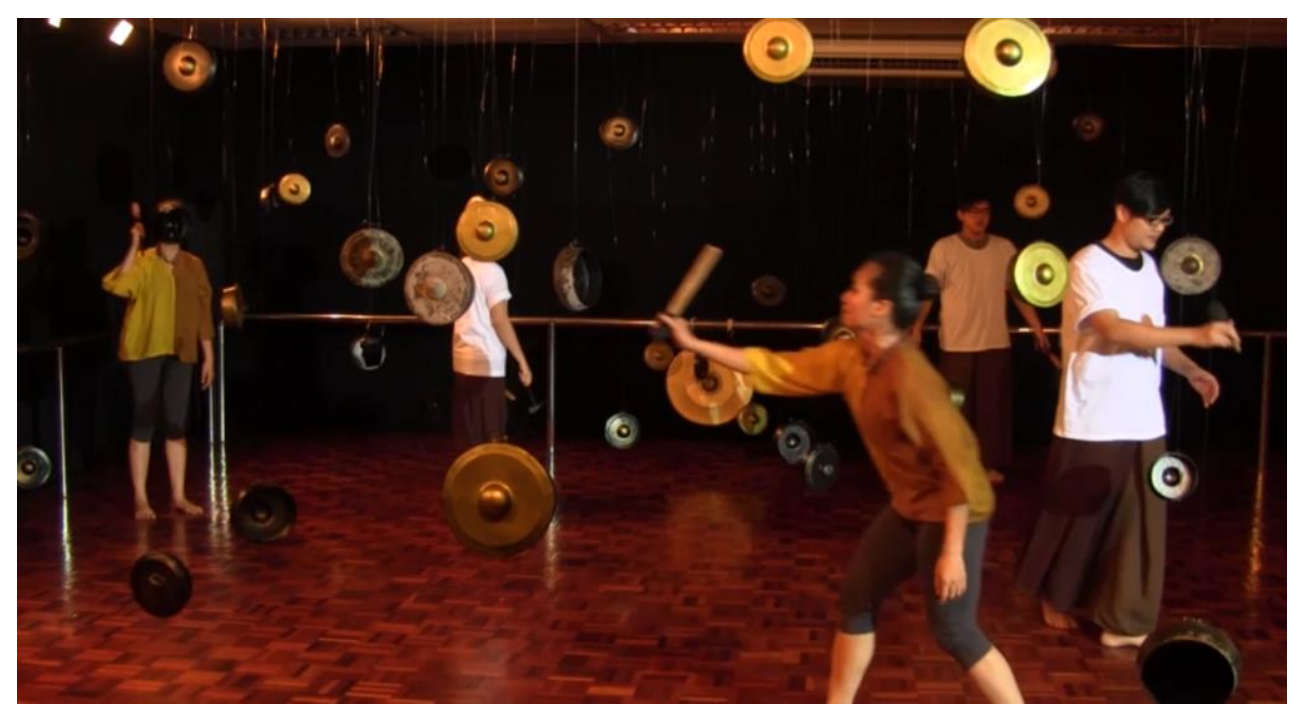

Figure 20. A scene portraying how the performers exploring the spatial acoustic of the setting to re-create an imaginary 'choir'.

Each performer continually imitated and responded to the sounds on the stage freely and in a more personal and imaginative way. Although the order was not fully restricted and was left to the preference of the performer, the procedure was that while playing or making a sound, whilst choosing and playing the instrument on stage, each performer had to re-imagine the instrument's sound that either they or the others created and recreate this with their voices.

The fifth event provokes a very strong local ritual sense of performance, forming an imaginary 'trio' setting inspired by the architectural setting and bringing the dance and musical dialogue onto the stage with a solo dancer and a sheng player (Figure 21). 


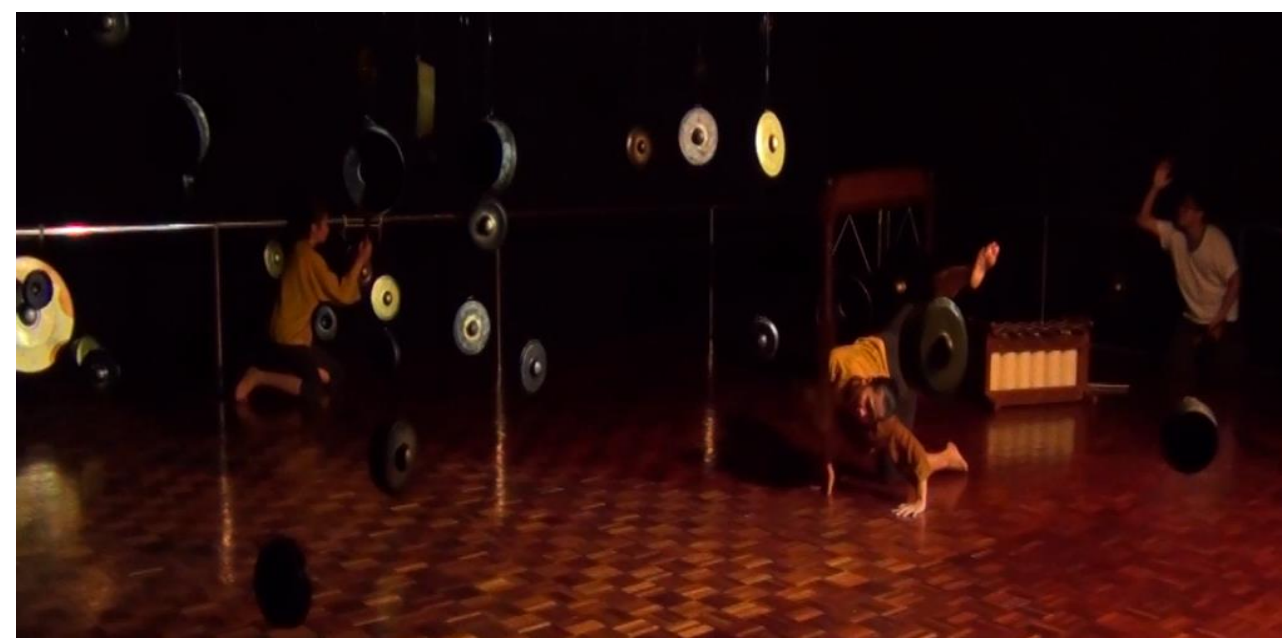

Figure 21. A scene demonstrating how the imaginary 'trio' setting is being conducted

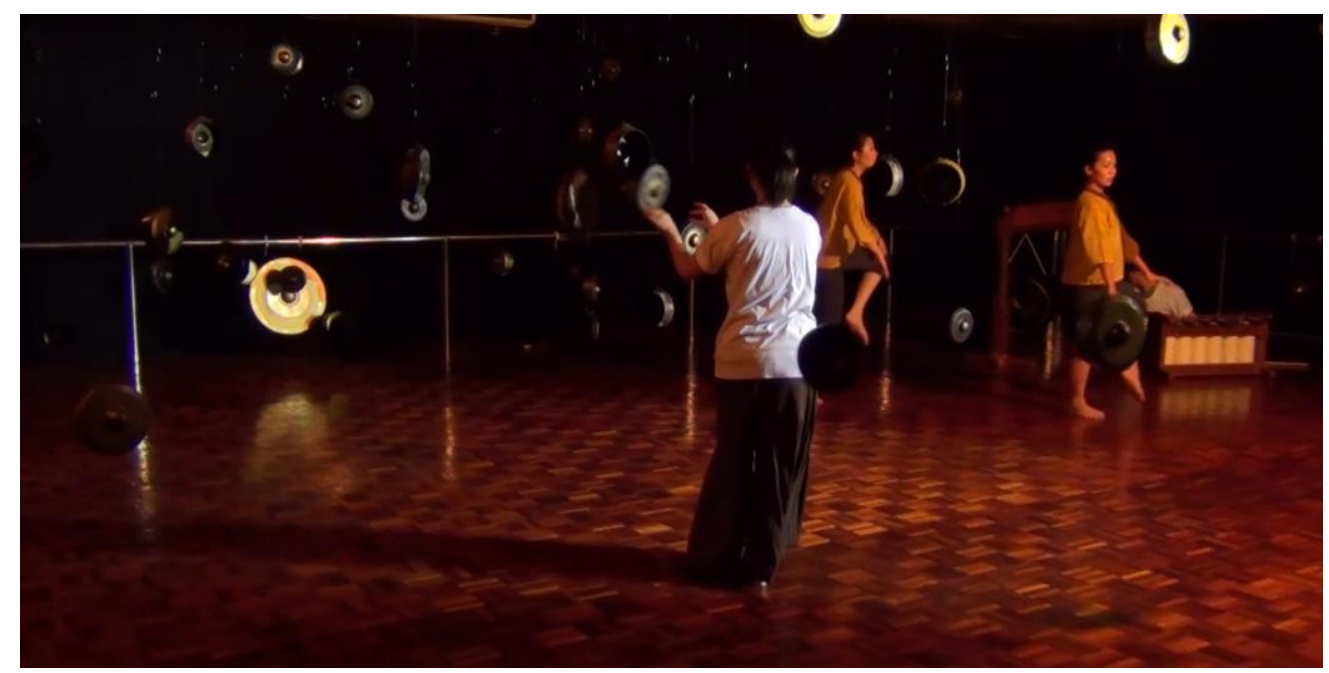

Figure 22. A scene depicting how the whirling gongs is being operated by one of the musicians

This gong trio, led by one of the musicians acting like a conductor, creates a murmuring speech or chant-like conversation that is shaped and intercut by a sometimes interlocking rhythmic pattern. It is performed in an improvisational manner whilst continually corresponding and integrating indirectly and intermittently with other elements, including the dance solo and the music played by the player. This spatial idea, pairing elements of Chinese interior architecture and musical elements, and formed by the positioning of instruments and performer at opposing positions in the room, shows another example of how I integrated and extended the hybrid elements into my work. 
The last section is a finale in which some of the previous materials and activities, including the 'canon' pattern of choreography at the opening as well as the scene of twisting gongs, are recapitulated (see Figure 22).

The highlight of this section was the conversation that the whirling gongs themselves created by chance This conversation happened during a moment of accidental contact between the whirling gongs, starting from approximately 17:10, when one of the musicians joining the stage action started to move the whirling kulintangan one by one freely across the stage. With so much movement on stage, the kulintangan would sometimes accidently come into contact with each other or one of the performers. The resulting chance elements created an interesting situation in which the whirling kulintangan on stage seemed to be talking not only to other kulitangan but also to be interacting with the dancers and the music from the ensemble as equal partners, echoing sound and movement with an irregular dialogue of contrapuntal textures.

Associated with different artistic forms of languages between sounds and movements, this constellation of musical activities undergoing within a certain structural frame engaged with improvisational approach has been constantly punctuating moments in which the character, the identity of the work itself seemed to be re-established throughout the working processes. This transformative experience provided me with a deeper understanding of the holistic interconnectivity between my work and others and how the collaboration forms and hybridises material through which a new structural form has been arisen, which it resonances to what Pugh Kitingan (2017) addressed in her article 'Source, sounds, and meanings of turali (noseflute) music in Dusunic cultures of Sabah', of how turali music is being shaped and re-contextualized over the time by the personal artistry of the performer. What I have encountered and discovered throughout the discourse, by applying the idea of wayfaring to my compositional practice, is an ever deeper and more complex understanding of the dimensions of 'in-betweenness' in which one's cultural identity, language and creativity transforms and evolves through the process of emergence, a movement, an experience of emergent creative energy in which one sees a dynamic relation between the 'positive' aspects of something coming into being as well as the 'negative' ground from which it arises.

\section{Conclusion}

In response to the earlier discussion from Tim Ingold about the 'skill' relating to the practice of cultural exchange, the starting point of this project can be actually traced back to the moment especially when I discovered the 'otherness' from the sketch drawn by the dancer. This was the breaking point at which I started realising the emergent power of cultural exchange through collaboration through which the score I created for the dancer has been transcended to create a new form of vocabulary through the power of (re)translation. Such encounter became even stronger during the live performance session when the materials and the energies that have been activated between the performers have been intertwined and dissolved until a point at which they are hardly identified with any one party but the 'becoming' of itself. 
One of the challenges that I have encountered throughout the exchange especially during the improvisational performance was that although this notion of intercultural exchange seemed ideal as a 'passport' to cross into another territory to gain knowledge for my work, the result of the exchange itself in fact seemed to be pushing me towards an unknown place that does not belong to any particular party but itself. This confusion happened especially during the live, improvisational performance when we barely explained which material had we contributed or borrowed from others, leading me to questions of what sort of musical surface I should look at; what sort of dialogue should be held, delivered and presented; and how should I, as a composer, respond to these in my musical works through musical notation in my (future) work.

\section{Endnotes}

${ }^{1}$ Merdeka, a Malay word which literally means Independence Day.

${ }^{2}$ Further reading can be found in Khairuddin, Yong, B., \& Sabapathy (2012).

${ }^{3}$ The term muhibah is derived from an Arabic word $h u b b$, signifying a universal love or affection. Further definition and reading can be found in Ibrahim (2013).

${ }^{4}$ This was a historical event gathering and promoting artists and composers within the Southeast Asia region held in Kuala Lumpur, Malaysia from Friday $27^{\text {th }}$ to Sunday $29^{\text {th }}$ November 2009, organised by Goethe-Institute Malaysia and the Malaysian Composers Collective, together with event co-organiser SEGi College Subang Jaya.

${ }^{5}$ North Borneo (or east-Malaysia), the place where I was born and lived.

${ }^{6}$ Abels (2015) discusses how dance and gongs are an essential core for people to maintain their cultural identity. There is an experience of cultural self-recognition through movement and music whereby people retrieve personal/cultural memory through the 'encapsulated cultural signal' of the gong while the movement of the dance serves as a compass by which one navigates the people back to a cultural 'home'.

7 Kadazandusun traditional gongs, one of the popular percussive instruments found especially throughout South East Asia, are used in sets to play melodies.

\section{References}

Abels, B. (2015). Musicking home in the Southeast Asian island world. Contemporary Music Review, 35, 33-43.

Bhabha, H. (1994). The location of culture. London: Routledge.

Cary Y., L. (1999). Calligraphic couplets as manifestation of deities and markers of building. In E. John B. (Ed.), The embodied image: Chinese Calligraphy from the Jon B. Elliott collection (pp. 361-375). Princeton: The Art Museum, Princeton University.

Forsythe, W. (2011). Choreographic objects. In S. Spier (Ed.) William Forsythe and the practice of choreography: It starts from any point (pp. 90-94). London: Routledge.

Glover, R. \& Harrison, B. (2013). Overcoming form: Reflections on immersive listening. Huddersfield: University of Huddersfield Press.

Ibrahim, H. (2013, October). Muhibah for a sustainable framework of inter-religious relations in Malaysia. Poster presented at Joint Seminar between the Department of Usuluddin \& Comparative Religion, Kirkh, IIUM And Cismor, Doshisha University, Kyoto On 'Shariah, Governance and Interreligious Relations', $26^{\text {th }}$ October 2013 at the International Islamic University Malaysia. 
Ingold, T. (2000). The perception of the environment. London: Routledge.

Ingold, T. (2010). To learn is to improvise a movement along a way of life. [Seminar].

Retrieved from https://www.youtube.com/watch?v=lDaaPaK-N5o.

Ingold, T. (2015). The life of lines. Oxford: Routledge.

Jamal, S.A. (1982). Seni Lukis Malaysia-25 Tahun. Kuala Lumpur: Balai Seni Lukis Negara.

Kin-Yan, S. (2010). Calligraphic kinesthesia in the dancescape: Lin hwai-min's

cosmopolitical consciousness in the Cursive Trilogy. Dance Chronicle, 33 (3), 414441. doi:http://www.tandfonline.com/doi/abs/10.1080/01472526.2010.517496.

Lee, C.T. (2012). Chinese calligraphic thinking in my compositional work (unpublished Master thesis). Retrieved from http://eprints.hud.ac.uk/17532/1/ctileefinalthesis.pdf.

Melucci, A. (2015). Identity and different in a globalized world. In P. Werbner \& T. Modood (Eds.), Debating cultural hybridity: Multicultural identities and the politics of AntiRacism (pp. 58-69). London: Zed Books Ltd.

Pugh Kitingan, J. (2017). Sources, sounds and meanings of turali (noseflute) music in Dusunic cultures of Sabah. Malaysian Music Journal, 6(2), 1-28.

XdoctorbutcherX. (2010, Jan 1). Tim Ingold - to learn is to improvise a movement along a way of life (part 1). [Video file]. Retrieved from https://www.youtube.com/watch?v=1DaaPaK-N5o

Yee, I.1. (2012). Love me in my batik. In N. H. Khairuddin, B. Yong, \& T. K. Sabapathy (Eds.), Imagining identities: Narratives in Malaysian Art (pp. 262-278). Kuala Lumpur: RogueArt.

\section{Biography}

Lee Chie Tsang Isaiah is a composer, lecturer, and research Fellow of the Borneo Heritage Research Unit in the Faculty of Humanities, Arts and Heritage at Universiti Malaysia Sabah. $\mathrm{He}$ has currently finished his $\mathrm{PhD}$ in composition, funded by Universiti Malaysia Sabah (UMS) and The Malaysian Ministry of Higher Education (MOHE), at the University of Huddersfield (United Kingdom) with principal supervisor Professor Liza Lim and cosupervisor Professor Aaron Casiddy. His current work is concerned with exploring and reframing interdisciplinary perspectives related to hybrid oral traditions found in East Malaysia to provoke new possibilities for sounds, spaces and creativity in his compositional work focusing on music and dance collaborations with Indigenous Malaysian references, aural/oral traditions in Hakka poetry, and traditions of pattern making related to Borneo bead work. His music evokes the notion of energy as flowing movement and significant colour bringing together Asian performance aesthetics, western contemporary classical approaches as well as aspects of indigenous East-Malaysian (Kadazandusun) ritual forms. 